\title{
Economic Analysis and Evaluation of Energy-efficient Renovation of Existing Buildings Based on the Whole Life Cycle
}

\author{
Han Xue \\ Engineering Management Department of Henan Technical College of Construction, Erqi District, Zhengzhou, Henan, China
}

\begin{abstract}
There has long been a lack of understanding of the costs and benefits of energy-efficient renovation of existing buildings, which discourages the participation of stakeholders. This paper studied the energy-saving renovation of existing buildings, analyzed the incremental cost and incremental benefit based on the whole life cycle, and constructed the economic evaluation model of energy-saving renovation of existing buildings to provide a scientific theoretical basis for the economic evaluation of the energy-saving renovation of existing buildings and provide references for the decision-making of stakeholders, and promote the energy-saving renovation of buildings from an economic point of view.
\end{abstract}

\section{Introduction}

Sustainable development has become the common pursuit of human beings. The green revolution of energy saving and emission reduction has grown to be an inevitable trend of social development, which is taking place in the field of architecture. At present, there have been very few green buildings, requiring large-scale promotion. Compared with newly-built green buildings, the energysaving renovation of existing buildings is more economically efficient. Though the energy-saving renovation of existing buildings benefits the country and the people, the high initial investment demanded by the projects is exerting tremendous pressure on stakeholders, which is not conducive to the development of green buildings.At present, there are various existing buildings, most of which are non-energy-saving buildings with high energy consumption. When constructing the project, people tend to pay attention to the initial cost of the construction, and rarely consider the energy consumption cost of the building in actual operation. For energy-saving buildings, it is often difficult for people to intuitively feel how much energy-saving it is compared with non-energysaving buildings, and how much economic benefits it can produce.

This paper established a framework to study the economic benefits of energy-efficient renovation of existing buildings based on the life cycle, focusing on the investment recovery efficiency in the whole life cycle of energy-saving renovation projects. Also, the economic evaluation model of energy-saving renovation of existing buildings was constructed to provide theoretical basis for decision makers.

\section{The definition of whole life cycle cost}

\subsection{The definition of whole life cycle cost}

The whole life cycle refers to the process involving the conception, scheme design, operation and disposal.The life cycle of construction project covers the whole process of decision-making, design, procurement and processing of raw materials and components, construction, operation, maintenance, scrapping, demolition and recycling.

Therefore, this paper divides the whole life cycle into four stages, including decision making, construction, operation and maintenance, recycle and disposal.Life cycle cost refers to the total cost of a construction project in the process of decision-making design, construction, use and maintenance, recycling and scrapping.

\subsection{Significance of Life Cycle Cost}

As the cost and benefits in the later stage of the project account for a certain proportion in the life cycle cost, analysis of only one stage of the project would be incomplete. Energy-saving renovation projects generally feature higher costs during the construction and lower energy consumption in the operation. Currently, when stakeholders make economic analysis, evaluation and decision-making on energy-saving reconstruction of the existing buildings, the main content of the research is focused on the construction stage of the project. But stakeholders fail to consider the operation and maintenance of the project in the early stage of construction and after the transfer of the project, which serves as the reason for the lack of motivation for stakeholders to carry out energy-saving reconstruction. Therefore, it is more practical to conduct 
economic evaluation of energy-saving renovation projects based on the whole life cycle than focusing on one or two stages.

\section{Incremental cost of energy-saving renovation (CO)}

The life cycle cost of the renovation project covers the design, construction, operation and maintenance, recycling and disposal of the building. Public acceptance and recognition of the renovation project depends on the cost and subsequent benefits, that is, whether the benefits of the renovation exceed additional costs incurred in the renovation. The renovation cost discussed in this paper refers to the increased cost of green and energy-saving renovation compared with standard buildings, namely the incremental $\operatorname{cost}^{[1]}$.

\subsection{Incremental cost in the stage of design and decision making (COd)}

The incremental cost in the stage of design and decisionmaking mainly includes market survey, statistical and feasibility studies of renovation, overall evaluation of the building, project bidding, design of specific energysaving renovation schemes and other preliminary preparation.

\subsection{Incremental cost in the construction stage (COc)}

The incremental cost in the construction stage includes material, labor, depreciation of machines, site preparation, and temporary shed. For example, the thermal insulation taken for roofing, walls, doors and windows, and the increased cost of maintenance structures such as walls, doors and windows. In addition, while creating environmental benefits, energy-saving renovation projects will also produce certain environmental pollution, including noise pollution and pollutants released by building materials. It should also be listed and included in incremental costs ${ }^{[2]}$.

\subsection{Incremental cost in the operation stage(COo)}

The incremental cost in the operation stage refers to the incremental cost incurred in the delivery of the renovated building, which mainly takes into account the repair, maintenance and management of the building in the operation stage. For example: the replacement cost of some equipment and parts in the later period; expenses incurred in formulating the management system that saves energy, water, and materials, and the management system of domestic garbage, waste gas and sewage; the cost of regular professional training and assessment for management personnel; regular statistical analysis of energy consumption and fees of energy audit.

\subsection{Incremental cost in the recovery stage (COr)}

The incremental cost in the recovery stage mainly refers to the cost of demolishing existing buildings at the end of the life cycle, a cost above the benchmark of demolishing buildings. This part of cost mainly refers to the extra cost incurred to reduce the adverse impact on the environment after demolition by classifying and recycling the construction waste and saving resources.

Therefore, the incremental cost $\mathrm{CO}$ of energy-saving renovation is given by:

$\mathrm{CO}=\mathrm{COd}+\mathrm{COc}+\mathrm{COo}+\mathrm{COr}$

Incremental cost of energy-saving renovation (CO)

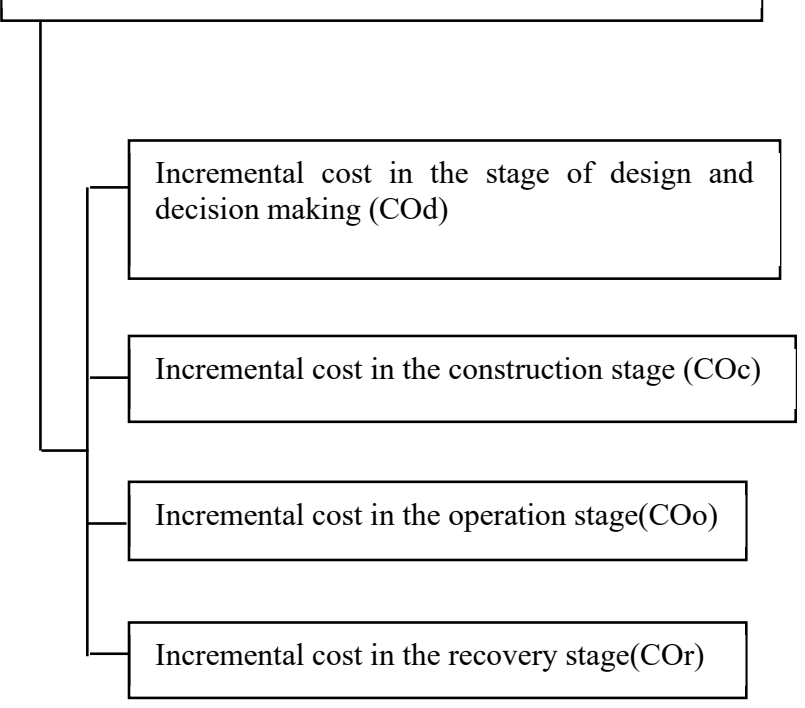

Fig 1. The composition of the incremental cost of energysaving renovation

\section{Incremental income of energy-saving renovation $(\mathrm{CI})$}

The incremental income refers to the total benefits generated by energy-saving renovation of existing buildings compared with before renovation. In the renovation, the application of energy-saving and environmental protection technologies and materials would add to the construction cost. However, it will significantly reduce the energy consumption in the longterm operation of the building, which is defined as the incremental benefits created by the energy-saving renovation projects. This paper divided the evaluation index into three categories: direct economic benefit, environmental benefit and social benefit ${ }^{[3]}$.

\subsection{Incremental economic benefits of energy- saving renovation (Cle)}

Incremental economic benefits refer to the increase of economic benefits and the reduction of operation costs in the whole life cycle of the building as a result of energy conservation.

The economic benefits of building renovation include the lower cost of coal burning in winter and air conditioning in summer due to improvement in the thermal insulation performance of building envelope. In 
addition, it is also supported by preferential policies, subsidies and other rewards. The above-mentioned benefits are defined as explicit economic benefits. However, there are implicit economic benefits. For example, the introduction of thermal insulation layer to the exterior of the residential walls, waterproof and thermal insulation renovation of roofs, and enhancement of air tightness of doors and windows also increased the value of residential buildings. The renovation fixed the cracking and seepage of the outer wall of the building and improved the damp and moldy conditions inside the house. The functions of the building could better meet the needs of users, improving user satisfaction, extending the whole life cycle of the building, and enhancing the overall values of the building.

\subsection{Incremental environmental benefits of} energy-saving renovation (Clev)

The environmental benefits of the renovation projects include reduced energy consumption, emission of pollutants and adverse impact on the environment during the operation of the building, thus generating the environmental benefits. For example, reduced emission of harmful gases during operation, improved air quality, and less adverse impacts from the greenhouse effect, such as desertification, melting glaciers at the north and south poles and raising sea level.

\subsection{Incremental social benefits of energy-saving renovation (Cls)}

The social benefits refer to benefits brought by renovation of the envelop and reduced pollutant emission from energy consumption, including improved living environment and better life quality of residents.

Therefore, the incremental benefit CI of energy-saving renovation is given by:

\section{$\mathrm{CI}=\mathrm{CIe}+\mathrm{CIev}+\mathrm{CIs}$}

Incremental income of energy-saving renovation $(\mathrm{CI})$

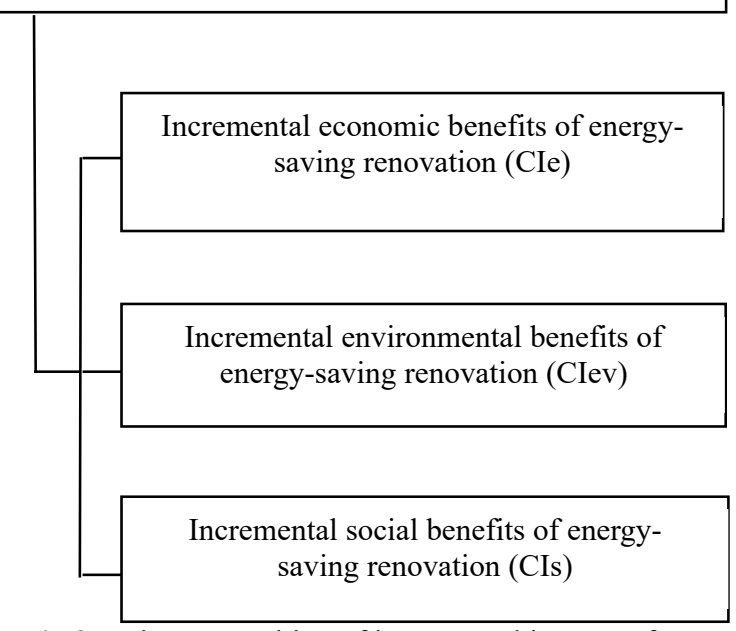

Fig 2. The composition of incremental income of energysaving renovation

\section{Cost-benefit evaluation model}

This paper evaluated the cost-benefit of the existing building renovation projects using the financial evaluation method. Considering the time value of the capital, the financial net present value and dynamic investment payback period were used for the evaluation.

\subsection{Financial net present value}

Financial net present value means that based on the established discount rate, the incremental cost is subtracted from the incremental benefit of each year in the whole life cycle of the project, then discounted back to the starting year of construction. Finally, the sum of the accumulated values is obtained.

The calculation formula of financial net present value is:

FNPV $=\sum_{\mathrm{t}=0}^{\mathrm{n}}(\mathrm{CI}-\mathrm{CO})_{\mathrm{t}} /(1+\mathrm{i})^{\mathrm{t}}$
in which:

FNPV_- Financial net present value;

(CI-CO)t - The difference of incremental benefit minus incremental cost in year;

i- Annual discount rate;

The criterion to evaluate a project based on the financial net present value is: when the financial net present value is greater than or equal to zero, it indicates that the profit rate of the project is not lower than the discount rate of the investment opportunity cost, so the project is feasible; when the financial net present value is negative, the project is not financially viable.

\subsection{Dynamic investment pay-back period}

The dynamic investment payback period represent the period required for the incremental benefit of the project to offset the incremental cost.

The dynamic investment payback period is given by:

$\sum_{\mathrm{t}=0}^{\mathrm{Pt}}(\mathrm{CI}-\mathrm{CO}) /(1+\mathrm{i})^{\mathrm{t}}=0$

$\mathrm{Pt}=$ (The number of years when the present value of accumulated net cash flow is positive-1)+ Absolute value of the present value of accumulated net cash flow in the previous year / Present value of net cash flow in the year showing positive value

in which:

(CI-CO)t - The difference of incremental benefit minus incremental cost in year $t$;

$\mathrm{i}$ - annual discount rate

$\mathrm{Pt}$ - Dynamic payback period (year)

The smaller the $\mathrm{Pt}$, the shorter the time needed to recover the incremental cost from the incremental revenue of the renovation project. The criterion to judge whether a project is feasible is to compare it with the benchmark payback period. When the dynamic payback period is less than or equal to the benchmark one, the incremental benefit of the project can recover the incremental cost in the required time, so the project is feasible; if the dynamic payback period is longer than the benchmark payback period, the incremental benefit of the project cannot recover the incremental cost in the required time, so the 
project is not feasible.

It should be pointed out that from the above formula, in addition to the incremental benefit and incremental cost of the project, the discount rate will also affect the financial net present value and dynamic investment payback period. In general, when the incremental cost and benefit have been determined, higher discount rate means smaller financial net present value and longer dynamic investment payback period; the lower discount rate represents larger financial net present value and shorter dynamic investment payback period. Therefore, it is essential to determine a reasonable discount rate in the cost-benefit evaluation.

Table1. Evaluation and judgment criteria.

\begin{tabular}{|c|c|c|}
\hline Evaluation & Calculation formula & Judgment criteria \\
\hline \multirow{2}{*}{ FNPV } & \multirow{2}{*}{$\mathrm{FNPV}=\sum_{t=0}^{\mathrm{n}}(\mathrm{CI}-\mathrm{CO})_{\mathrm{t}} /(1+i)^{t}$} & $\mathrm{FNPV} \geqq 0$, the project is feasible \\
\cline { 3 - 3 } & \multirow{2}{*}{$\sum_{t=0}^{\mathrm{Pt}}(C I-C O)_{t} /(1+i)^{t}=0$} & $\mathrm{FNPV}<0$, the project is not financially viable \\
\cline { 3 - 3 } & & $\begin{array}{c}\mathrm{Pt}>\text { the benchmark payback period,the project is not } \\
\text { financially viable }\end{array}$ \\
\hline
\end{tabular}

\section{Conclusion}

This paper analyzed the incremental costs and benefits in the whole life cycle of energy-saving renovation projects of existing buildings, and established the economic evaluation models with financial net present value and dynamic payback period as an index, which provides a theoretical basis for the stakeholders of renovation projects to understand the incremental costs and benefits of renovation, and assists the government, relevant departments and developers in decision-making. It should be noted that this paper made only a qualitative analysis of the influencing factors, while the data quantification of the influencing factors needs further discussion.

\section{References}

1. Liu, Y,M. (2011) Cost-benefit Analysis of Energysaving Renovation of Existing Residential Buildings Based on LCCA. Journal of Civil Engineering, 10: 118-123.

2. Han,H,L. Hu,S. Ran,H,R.(2017) Study on the Incremental Cost and Benefit of Green Renovation of Existing Residential Buildings. Value Engineering, 36: 45-48.

3. Wu,D,R.(2020) Life Cycle Cost-benefit Analysis of Energy-saving Renovation of Existing Building Envelope. Beijing Forestry University,Beijing .

4. Zhu,Z. Li,Y,R. Chen,C.(2018) Analysis and Evaluation of Incremental Cost and Benefit of Energy Saving in Green Building Life Cycle. Architectural Economics,39: 113-116.

5. Liu,Y,Y. (2017)Study on Economic Analysis and Evaluation of Green Building Life Cycle . East China University of Science and Technology,Shanghai . 